\title{
Leadership development in the South African construction industry
}

\author{
Liphadzi, $\mathrm{M}^{\mathrm{a}}$, Aigbavboa, $\mathrm{CO}^{\mathrm{b}}$, Thwala, $\mathrm{WD}^{\mathrm{c}}$ \\ ${ }^{a}$ University of Johannesburg, Aukland Park, Johannesburg 2006, South Africa \\ ${ }^{b}$ University of Johannesburg, Aukland Park, Johannesburg 2006, South Africa
}

\begin{abstract}
The construction industry is one of the major industry in South Africa, due to its positive infrastructure impact to the economy. Like any other industry, strong leadership is fundamental for its growth. Moreover, in order to stay competitive, South African construction organizations must find a way to train their project and construction managers to become capable leaders in their specific disciplines. Hence, this study presents findings on how managers can be developed into leaders in the South African construction industry. The data used in this research were derived from both primary and secondary sources. The secondary data was collected via a detailed review of related literature. The primary data was collected through a well-structured questionnaire aimed at 150 projects and construction managers in the South African construction industry. 110 questionnaires were received and data was analysed using Statkon SPSS software, whereby frequencies, MIS and descriptive were attained. Findings revealed that, curricula education and qualification can help develop leaders in the South African construction industry. Followed by leadership training courses, taking responsibility as mangers, and accepting new challenges were seen as important, in addition internal motivation, professional and personal development. The study presents a background about the construction industry and the importance of effective leadership in the construction industry for construction management performance.
\end{abstract}

(C) 2018 The Authors. Published by Diamond Congress Ltd., Budapest University of Technology and Economics Peer-review under responsibility of the scientific committee of the Creative Construction Conference 2018.

Keywords:Construction leadership; Leadership development ; South Africa

\section{Introduction}

Leadership is one of the most critical elements for good project and construction management. The diverseness in activities and role players in the construction industry makes leadership more imperative, since leaders provide a directive or have influence on any organization or industry. Havenga [1] is of the view that, leaders inspire others to make decisions. Commonly, one can say that leadership is a process by which one person influences the thoughts, attitudes, and behaviors of others. South Africa, a country aggrieved by leadership challenges in different industries is always calling for leadership solutions. This always demands managers and entities to reinvent themselves or make way for new managers who are capable of being leaders in the construction industry. Good leadership helps our nation through times of challenges. It makes a business organization successful. It enables companies to fulfill its mission. On the contrary, the absence of leadership is equally dramatic in its effects. Without leadership, organizations move too slowly, stagnate, and lose their way [2]. With this background, leadership development becomes an integral aspect in developing managers into leaders in the construction industry. The paper gives clarity on leadership and leadership development in the South African construction industry, followed by presentation of the methodology and the findings before conclusions and recommendations are represented.

Corresponding author: Author email: liphadzi@hotmail.com 


\section{Leadership in the construction industry}

The principle of construction and project management is responsibility. This makes projects and construction managers vital to the development of any construction project. Not entirely stating that they do everything on a project. Conversely, it does imply that they have fundamental influence and responsibility on any project. Broadly analyzing the above we speak of leadership in the construction industry. Further, it is also apparent that the construction industry has a greater need for management and leadership understanding. Daft [3] stated that the complexity and the involvement of many team members in any construction project makes management and its leadership vital. Important in the sense that effective leadership is largely seen as one of the success factors in the construction industry [4]. In the study of leadership in construction, it is also important to note the distinct difference between leadership and management.

\subsection{Leadership and the South African construction industry}

The construction is a large-scale contributor of employment in South Africa and it also provides the physical infrastructure and it is the backbone for local economic activity. As an outcome, construction plays a fundamental role in the economic and social development of South Africa. Unfortunately, the legacy of apartheid has left the South African construction industry with a number of development and transformation challenges [5]. Limitations exist in the emerging sector with regards to the inability to access opportunities, finance and credit, as well as training with regard to leadership and management. Ofori [6] notes that the South African construction industry has been focused on management than in leadership. He further states that this orientation by South African construction firms and industry is resulting in a shortage of skillful 'project leaders' regardless of the large number of project managers produced. Ofori further stated that, low volume of leadership studies in the South African construction industry is due to the lack of knowledge of the industry on the part of social scientists and a lack of understanding of social sciences by those in the industry. However, in recent years, there has been an increasing appreciation of the significance of leadership and the role it plays in delivering effective construction projects. This growth of leadership in the construction industry has resulted in a slow but continuing increase in the number of publications on leadership and related topics [7]. The need for leadership and leadership development is undoubtedly of prominence in South Africa.

\section{Leadership development in the construction industry}

Bennis [8] noted that leadership development strategies are transitioning from the idea of teaching skills and competencies to teaching values and concepts. This immense shift is built on the idea that skills and competencies change from person to person, but the basic values and concepts are more common, leader to leader. Leadership development is driven by actionable information and individual accountability. As in the construction industry the construction environment has changed and it is more complicated, unstable and irregular [8]. Moreover, the skills needed for leadership have changed, more adaptive thinking abilities are of importance to the development of leaders in the construction industry. Methods of development haven't changed much, Petrie [8] stated that majority of managers are developed from on the job experience, training, coaching and mentoring. Price [9] insinuated that the potential sources of leadership development include observing, mentoring or coaching by seniors, reading or selfstudy, education courses during university, education courses in college, company training, and job experience. In addition, Bogus and Rounds [10] stated that managers can be better leaders from self- education, attending seminars, reading, watching, experience, and from having active organizational mentors. As stated in the last South African section, there is no longer just a leadership challenge, it is a developmental challenge in connection with how do we develop as managers and leaders. It is also important to note that organizations are increasingly reliant on HR departments to build a leadership framework for managers capable of leading in the $21^{\text {st }}$ century.

In supplement, Jarad [2] is of the view that construction organizations can develop leadership and management skills by developing a culture of teaching, mentoring, self-study, and frequent job changes. Companies can also use their own professional personnel to offer formal leadership and management training. Leadership development initiatives set the stage for organizational success by empowering employees to develop their skills and competencies. It improves retention, provides a foundation for succession planning and trains the next generation of leaders to focus on how managers lead, develop and partner with their employees. 


\subsection{Leadership development models}

Leadership research history has different leadership development frameworks that have been developed and studied, below are some of this models;

\subsubsection{Fiedler contingency model}

Fred fielder [11] created this model in the 1960s, he studied personality and characteristics. This model focuses on leadership style and the situational context.

\subsubsection{Navy leadership framework}

Richardson [12], stated that this framework underpins from humility, courage and commitment. The framework teaches future leaders to inspire their teams and to be disciplined.

\subsubsection{SHL leadership model}

The model recognizes that leadership is a collective function with organizations. Bartram [13] created this model with an intention of presenting both transformational and transactional factors for leadership development.

\subsubsection{Authentic Leadership model}

Luthans and Avolio [14], created this model which focuses on self-awareness and self-regulations attributes. The model shows ethical behavior and relational transparency factors.

\subsubsection{The Leadership Pipeline}

Ram et al developed the model to answer the succession planning challenges for leadership development. The model integrates leader development at each managerial level within an organization.

\subsection{Leadership development gaps}

Looking at the different models above it is important to note that most of this models are done within the developed countries' context, that understanding can be seen as a gap for the development of leaders within the South African construction industry. Research studies on construction leadership development lacks models and frameworks that factor in situational awareness, ethical behaviours, technological understanding and having entrepreneurial ability [9]. Individual developmental measure from one stage to the next is usually driven by restrictions in the current stage of appreciative development. When you are challenged with increased difficulty and challenges that can't be reconciled with what you know and can do at your current level, you are pulled to take the next step [15]. In addition, development accelerates when people are able to identify the assumptions that are holding them at their current level of development and test their validity.

\section{Research Methodology}

Research methodology studies the background of the research and the anticipated results in order to achieve significant research outcomes. Moreover, the selection of an appropriate research design involves several steps, beginning with recognizing the problem, purpose of the study and in depth literature review. This research adopted a quantitative approach which involved the use of a questionnaire. It is also vital to note that the data used in this study were derived from both primary and secondary sources. Burns and Grove [16] describes quantitative research as a formal, systematic process that describes and test relationships and examines causes among variables. In addition, Polit and Hungler [17] were of the view that quantitative research is a survey to obtain information from a sample of people by means of selfreport, whereby people respond to a sequence of questions posed to them by the researcher. The primary data was obtained through the survey method which used purposive sampling, while the secondary data was derived from the review of literature and archival records. The primary data was obtained through the use of a structured questionnaire 
survey. The questionnaire survey led to the compilation of the primary data. However, questionnaires were decided upon for this study for the following reasons: they require less time and energy to administer and they offer anonymity because the respondent's names are not required on the completed questionnaires. The format of the questionnaire had a section that identifies leadership development methods in the South African construction industry. Respondents had to select eminent methods that can be used for developing leaders in the construction industry, the selection was translated into frequencies and percentages and then ranked. This was distributed to a collective total of 150 projects and construction managers in the South African construction industry, Gauteng. It is vital to note that any research based on measurement must be concerned with the accuracy and dependability. A reliability coefficient demonstrates whether the test designer was correct in expecting a certain collection of items to yield interpretable statements about individual differences [18]. George and Shamas [19] notes that the value of the Cronbach's Alpha above 0.7 is acceptable for reliable analysis. Description of reliabilities of all scales used in the study indicated a Cronbach Alpha of above 0.7. The data presentation and analysis made use of frequency distributions and percentages of all the respondents.

\section{Findings and Discussions}

Findings from the 110 usable questionnaires revealed that $52 \%$ of the respondents were project managers and $48 \%$ of the respondents were construction managers. Furthermore, $69.5 \%$ of the respondents are currently involved in projects in the range $0-5$ projects, $16.2 \%$ of the respondents are involved in projects in the range of 6-10.

\subsection{Methods and ways that develop leaders in the construction industry}

It is apparent from the table below that $89 \%$ of the respondents' said that education/skills and qualifications are important methods that can help with developing leaders in the South African construction industry. This factors were ranked first. Of the respondents $73 \%$ regarded leadership training courses as the second ranked method for leadership development; $72 \%$ selected taking responsibility $(R=3)$ and $55 \%$ indicated new challenges $(R=5)$. New experiences and financial benefits were ranked $8^{\text {th }}$ and $9^{\text {th }}$ respectively.

Given that at most instances it is employees and managers who market, create products, make decisions and sustain construction projects, the development of human resources is fundamental to the success of the global organization. Literature reviewed that leadership development is an unceasing, systematic process designed to expand the capacities and awareness of individuals, groups, and organizations in an effort to meet shared goals and objectives [20]. Jarad [2] was of the view that, the primary purpose of most leadership development interventions was to improve individual managerial skills and on-the-job performance. In addition, Jarad [2] stated that construction organizations can develop leadership skills by developing the culture of teaching, mentoring and being exposed to new challenges.

\begin{tabular}{|c|c|c|}
\hline Ways to develop leaders in construction & $\mathrm{N} / \%$ & Rank \\
\hline Education / Skills / Qualifications & $89 \%(\mathrm{~N}=97)$ & 1 \\
\hline Leadership training courses & $73 \%$ & 2 \\
\hline Taking responsibility & $72 \%$ & 3 \\
\hline Learn new skills that enhances capability & $56 \%$ & 4 \\
\hline New challenges & $55 \%$ & 5 \\
\hline Inspirations from within the current leadership & $54 \%$ & 6 \\
\hline Clear guidelines or directions by current leadership & $51 \%$ & 7 \\
\hline New experiences & $50 \%$ & 8 \\
\hline Financial benefits, reward and incentives & $42 \%(\mathrm{~N}=46)$ & 9 \\
\hline
\end{tabular}




\subsection{Leadership development factors}

It is patent from the findings (see table 2 below) that internal motivation is required to develop yourself as a leader, this factor was ranked first with a mean score of 4.32; ongoing personal and professional development was ranked second with a mean score of 4.12; evident leadership skills was ranked third with a mean score of 4.11; succession planning and strategy was ranked fourth with a mean score of 4.10; and personal financial gains was ranked the least with a mean score of 3.63. Literature reviewed indicated that the first step in developing a leadership development strategy is to determine why the organisation believes that this is a strategy that should be pursued, in other words, what it hopes to achieve with the strategy, moreover leadership development initiative cannot be successful unless it clearly targets a specific business goal [9]. Bogus and Rounds [10] suggest that employees can be better leaders from self-education, attending seminars, reading, watching, experience, and from having active organizational mentors.

Table 2. Leadership development factors

\begin{tabular}{lll}
\hline Leadership development factors & Mean & Rank \\
\hline $\begin{array}{l}\text { Internal motivation is required to develop yourself as a } \\
\text { leader. }\end{array}$ & 4.32 & 1 \\
Ongoing personal and professional development. & 4.12 & 2 \\
It is important for someone to demonstrate leadership skills & 4.11 & 3 \\
in order to be promoted to a leadership position. & & \\
Succession planning and strategy. & 4.10 & 4 \\
It is important for a leader to have formal leadership training. & 4.07 & 5 \\
Personal gains have an impact on developing leaders. & 3.63 & 6 \\
& & \\
\hline
\end{tabular}

\section{Conclusions and further research}

The study explored leadership development methods, ways and factors. The study revealed that there is a dire need to develop leadership skills of construction project leaders in the South African construction industry, this translated to be the main goal of this paper. Regardless of the fact that majority of the respondents agreed to having attended leadership development trainings, literature revealed that the development of leaders in the construction industry is a trip which requires fixed attention. Literature further revealed that leaders can be developed by self-education, attending leadership seminars, job experience, being coached and mentored. From the survey results obtained from the respondents, it was observed that education and qualification can help develop leaders in the construction industry. Followed by leadership training courses, taking responsibility, new challenges, internal motivation, professional and personal development, succession planning and strategy. It is worth noting that few respondents chose financial benefits as significant to helping them improve as a leader, yet companies use this as the most common way to retain and reward leaders. However, the research in the near future can focus on developing leadership development frameworks which are contextualized for the construction industry, this can be done by also providing a clear relationship between different methods and the developed frameworks.

\section{Acknowledgements}

This study was supported in part by the National Research Fund and the University of Johannesburg.

\section{References}

[1] Havenga, R. (2005). The new leadership challenge: Teaming principles with practices in times of change. Management Today.

[2] Jarad, G. H., 2012. 'The construction manager leading characteristics for the success of construction projects in the Gaza Strip' Master's Thesis, The Islamic university of Gaza

[3] Daft, RL 2007, Management, 6 edn, Thompson South-Western, OH

[4] Odusami, K. T., Iyagba, R. R., \& Omirin, M. M. (2003). The relationship between project leadership, team composition and construction project performance in Nigeria. International Journal of Project Management, 21 (7) 
[5] Construction Industry Development Board (CIDB). (2012). The Construction Industry as a Vehicle for Contractor Development and Transformation. Pretoria, South Africa: CIDB

[6] Ofori, G. (2008). Construction in developing countries. Construction Management \& Economics, 25(1)

[7] Ofori, G., (2015), 'The construction industries in developing countries', In Ofori, G. (Ed.) New Perspectives on Construction in Developing Countries. Abingdon: Spon, pp. 1-16, 2012

[8] Petrie, N. (2014). Future trends in leadership development. Centre for creative leadership, White Paper

[9] Price, JJ. (2009). The Conception and Operationalization of leadership in construction companies, Masters Degrees Thesis, UNISA

[10] Bogus, S. M., \& Rounds. J. L. (2006) 'Incorporating leadership skill development in construction training programs', Proceedings of the 2nd Specialty Conference on Leadership and Management in Construction, May 2006, Grand Bahama Island, Bahamas

[11] Fielder, F. (1991), Improving Leadership Effectiveness: The Leader Match Concept, Wiley

[12] Richardson, D. (2012), Navy Leadership Framework: Navy Leadership, Wiley

[13] Bartram, S. (2014), SHL leadership model: SHL Group

[14] Luthans \& Avolio, (2003), An authentic leadership development model: Journal of human resources, Wiley

[15] McGuire \& Rhodes, (2009), Outline six steps they recommend to develop leadership cultures: The Inside-Out, The Leadership Transformation

[16] Burns \& Grove. S (1993), The practice of nursing research: Journal of human resources, Sanders

[17] Polit \& Hungler (1999), Nursing research: Principles and methods. $6^{\text {th }}$ edition. Philadelphia: Lippincott

[18] Cronbach, L. (1951). 'Coefficient alpha and the internal structure of tests'. University of Illinois, Psychometrika

[19] George, O., \& Shamas, R. (2012), leadership and Construction Industry Development in Developing Countries', Journal of Construction in Developing Countries, 1(2)

[20] Allen, S. J., \& Roberts, D. C. (2011), 'Our Response to the question: Next steps in clarifying the Language of Leadership Learning', Journal of Leadership Studies, 5. (2), pp. 65-70 